\author{
Magne Rogne \\ Universitetet i Stavanger
}

DOI: http://dx.doi.org/10.5617/adno.7903

\title{
Norskfaget i grunnskulelærarutdanningane - nyare utviklingstrekk
}

\begin{abstract}
Samandrag
Lærarutdanningane i Noreg har gått igjennom hyppige reformer dei siste tiåra. Ein har fått mange strukturelle endringar, og det er forska lite på kva som skjer med innhaldssida i faga. I denne artikkelen blir faglege utviklingstrekk i norskfagets læringsutbyteformuleringar systematisk undersøkt. Hovudmaterialet er nasjonale retningslinjer for grunnskulelærarutdanningane 1-7 og 5-10 frå 2010 og 2016. Resultata peikar mot fire sentrale utviklingstrekk i eit ustabilt norskfag, der mange nye emne kjem inn og mange etablerte går ut.
\end{abstract}

Nøkkelord: norskdidaktikk, norskfaget, lærarutdanning, faghistorie

\section{Norwegian in Initial Teacher Education - Recent Developments}

\begin{abstract}
Initial teacher education (ITE) in Norway has been frequently reformed in the last decades. ITE has undergone a number of structural changes, and not much research is done concerning the changes in content of the different subjects. This article systematically inquires into the change of content in Norwegian as a subject in ITE. The main material consists of the national curriculums for ITE for grades 1-7 and 5-10 from 2010 and 2016. The results point to four key characteristics in the development of an unstable Norwegian subject, where new topics have replaced many traditional ones.
\end{abstract}

Keywords: norwegian didactics, Norwegian curriculum, initial teacher education, subject history

\section{Norskfaget i grunnskulelærarutdanningane - nyare utviklingstrekk}

Lærarutdanninga i Noreg har vore igjennom to store strukturelle endringar dei siste ti åra - ein fekk innføringa av to grunnskulelærarutdanningar (1-7 og 5-10) i 2010, og deretter overgangen til masterutdanningar frå 2017. Desse strukturelle endringane har òg påverka norskfaget, samstundes som faget har hatt ein del interne utfordringar. I rapporten Framtidas norskfag vart det i 2006 slått fast at 
«Norskfaget i allmennlærarutdanninga er i høg grad kjenneteikna ved emnetrengsel» (Utdanningsdirektoratet, 2006, s. 74). Utfordringa var at studiet skulle femne både om faglege emne og fagdidaktikk, samt kvalifisere for undervisning i alle dei ti åra i grunnskulen. Breidda i faget omfatta m.a. språk, litteratur, digital kompetanse, norsk som andrespråk og utvikling av ferdigheiter i munnleg, lesing og skriving.

Med dette perspektivet som bakgrunn kan det vere interessant å sjå korleis innhaldssida av faget har endra seg ved dei to lærarutdanningsreformene som har kome etter rapporten. I denne artikkelen skal endringane i læringsutbyteformuleringar for norskfaget systematisk undersøkast for å avdekke faglege utviklingstrekk på nasjonalt nivå. Materialet til artikkelen er difor henta frå dei nasjonale retningslinjene for norskfaget (KD, 2010b,c; UHR, 2016a,b). Først kjem ein kort historisk gjennomgang av fagutviklinga og faget si stilling i lærarutdanninga, før faginndeling og faglege tematiske kategoriar blir drøfta. Deretter blir materialet og metoden presentert, og så kjem analysar, drøfting av resultat og ei kort avslutning. ${ }^{1}$

\section{Historisk bakgrunn}

Norskfaget i grunnskulelærarutdanningane har sine røter frå faget «Modersmaalet» i statsseminara som vart oppretta i kvart stift frå siste halvdel av 1820-åra. I reglementa for desse utdanningane var lesing, språklære og skriving dei sentrale emna i faget (Dahl, 1959; Madssen, 1999, s. 158ff). I 1890 får me for første gong ei lov om lærarutdanning i Noreg, og her var det ei vektlegging av emna litteraturkunnskap, språkkunnskap og dugleik i skriftleg og munnleg framstilling. Desse emna var dei sentrale i norskfaget fram til 1965. Historiske perspektiv var viktige både i litteratur- og språkkunnskap, men forsvann ut i dei obligatoriske delane etter kvart: oldnorsk/norrønt i 1965, språkhistorie i 1999 og litteraturhistorie i 2003 (Rogne, 2005, s. 51).

Presset på dei historiske tilnærmingane kan nok til dels forklarast med emnetrengsel. Frå 1965-planen kom det nye emne ved kvar reform, til dømes utvida sjangerlære, barnelitteratur og barnespråk i 1965, språkbruksanalyse i 1974, språksosiologi og normering 1980, EDB i 1986, tekstlingvistikk, elevtekst, norsk som andrespråk og biletspråk i 1992, og auka fokus på leseinteresse i 1999. I 2003 kom historiske tilnærmingar inn igjen, men denne gongen hovudsakleg som faghistorie. Dei nye emna som kom inn, vart som regel ein varig del av faget (Rogne, 2005, s. 52).

Når det gjeld skjønnlitteraturen, peikar Pål Hamre på at den hadde sin klassiske periode i norsk skule frå 1889-ca. 1970. Dette biletet gjeld stort sett for lærarutdanninga òg, men med eit oppsving i 1992-planen. I 2003 stod

\footnotetext{
${ }^{1}$ Takk til Pål Hamre ved Høgskulen i Volda for gjennomlesing og kommentarar.
} 
skjønnlitteraturen svekt tilbake, vart sidestilt med sakprega tekstar og planen bar preg av eit instrumentelt syn på lesing. Historiske, etiske og estetiske perspektiv ved lesinga vart nedtona (Hamre, 2014, s. 454, 474 og 485).

Ein annan sentral tendens er didaktiseringa av faget. Frå 1890 hadde ein metodisk undervisningstrening i øvingskular, men særleg på studentlinjene såg ein etter kvart små endringar i retning av ei meir teoretisk, fagdidaktisk tilnærming. Frå 1965 fekk ein eigne metodikktimar, der dei norskdidaktiske måla var sentrale. I 1970-åra fekk ein eigne norskdidaktiske kurs, og desse vart etter kvart integrert i sjølve faget. Seinare vart fagdidaktikken stadig viktigare, og i 2003-planen var han det dominerande emnet, med klart flest læringsutbyteformuleringar (Rogne, 2005, s. 52; jf. Hamre 2014, s. 433, 455, 474).

Når det gjeld stillinga til norskfaget i lærarutdanningane, var faget det klart største fram til 1974, då det forsvann ut som obligatorisk eining. I 1980 kom det inn igjen med 25 \% av eit studieår, medan det frå 1992 har vore ei halvårseining med obligatorisk norsk. (Rogne, 2005, s. 49f) Med innføringa av programma 1-7 og 5-10 i 2010 forsvann igjen norskfaget ut som obligatorisk fag, denne gongen på 5-10 (KD, 2010a). På 1-7 heldt ein fram med eit halvt år obligatorisk norsk. Desse ordningane vart vidareført i 2017 (KD, 2016a; KD, 2016b).

Eit siste historisk poeng skal takast med her knytt til inntakskrav og studielengd. Frå 1890 var lærarseminaret toårig med opptaksprøve, men utan krav om studenteksamen (examen artium). I 1902 vart utdanningane utvida til tre år, ein byrja å nytte namnet lærarskule og studentar med artium kunne gå inn det siste året. Fireårig lærarutdanning og eiga toårig studentlinje vart innført i 1930. Desse to retningane vart i 1973 slått saman til ei treårig utdanning med krav om artium for alle. I 1992 vart utdanninga fireårig, og i 1999 vart lærarutdanningslova integrert i universitets- og høgskulelova. Frå 2010 vart grunnskulelærarutdanninga delt i to, ei for klassane 1-7 og ei for klassane 5-10 i grunnskulen. Eit førebels høgdepunkt vart så innføring av femårig utdanning med mastergrad frå 2017 (Rogne, 2005, Munthe \& Rogne, 2016). Krava til inntak har òg blitt skjerpa dei siste åra, med poengkrav på 35, samt tre i norsk og matematikk frå 2005. Frå 2016 auka ein dessutan kravet frå tre til fire i matematikk, òg for dei studentane som valde norsk på 5-10-utdanninga (KD, 2014).

\section{Fag, faginndeling og kategoriar}

Dei siste tiåra har det blitt vanleg å sjå på lærarutdanningsfaget norsk som eit eige fag, med andre mål, vektleggingar og sosiale praksisar enn skulefaget norsk og vitskapsfaga som ligg til grunn for disiplinfaget nordisk språk og litteratur. Dei kan sjåast som ulike praksisfellesskap (Smidt, 2018, s. 145ff). Det betyr likevel ikkje at dei ikkje har påverknad på kvarandre (jf. Madssen, 1999, s. 36f, Ongstad, 2012, s. 30f), eller at dei ikkje deler mange felles historiske røter (jf. Nordstoga, 
2003, s.41ff). Her er ikkje målsetjinga å samanlikne desse ulike faga, men å studere den faginterne utviklinga i lærarutdanningsfaget norsk i grunnskulelærarutdanningane. Dermed kan den historiske gjennomgangen av dette faget vere eit godt utgangspunkt for kategorisering av innhaldselement, støtta med innsikter frå forsking knytt til lærarutdanning, skulefaget norsk og disiplinfaget nordisk språk og litteratur.

Eit sentralt drag med L1-faga internasjonalt er at språkkunnskap har ei ganske dominerande rolle (Ongstad, 2012, s. 34). Viktige element i språkstudium har tradisjonelt vore fonologi, morfologi, syntaks og semantikk, men dei siste tiåra har òg emne som ortografi, tekstgrammatikk, pragmatikk, retorikk og norsk som andrespråk kome med i grammatiske framstillingar for lærarstudentar. Dei fleste av dei tek òg opp forskjellar mellom målformene bokmål og nynorsk, særleg i morfologien. (jf. Kulbrandstad, 1998; Iversen mfl., 2004; Maagerø, 2005; Nergård \& Tonne, 2008; Rønning mfl., 2014; Budal, 2015). Vidare har språkhistorie og dialektlære/sosiolingvistikk utgjort ein viktig del av norskfaget på ulike nivå (jf. Hårstad, 2016; Bjellås, 2014). Til dette kjem kunnskap om andre språk enn norsk. Her har nabospråka (særleg svensk og dansk) tradisjonelt vore dei viktigaste, men dei seinare åra har òg samisk og andre nasjonale minoritetsspråk fått noko innpass (jf. Delsing \& Åkesson, 2005, s. 105; Følgjegruppa, 2013, s. 79ff).

Litteraturkunnskap er eit anna emne som går igjen i mange av L1-faga internasjonalt (Ongstad, 2012, s. 34). Den historiske gjennomgangen syner òg at det har vore sentralt i norskfaget i lærarutdanninga gjennom lange periodar. Sveinung Nordstoga peikar på «[...] tolking av skjønnlitterære tekstar, barne- og ungdomslitteratur, litteraturhistorie, litteratursosiologi, populærlitteratur og drama [...]» som viktige element i litteraturdelen av norskfaget (Nordstoga, 2003, s. 14).

Tekstkunnskap kjem som nr. 3 av emna som Sigmund Ongstad framhevar i L1-faga internasjonalt (Ongstad, 2012, s. 34), og det skal takast med her sidan det har vorte sentralt i norskfaget både i lærarutdanningane (jf. Hamre, 2014, s. 476; Nordstoga, 2003, s. 9) og i skulen (jf. Aase, 2005; Rogne, 2008) dei siste tiåra. Særleg har ei fornya interesse for sakprosa og sjanger, samt ei aktualisering av faget gjennom inkorporering av multimodale tekstar og digitale tekstar, ført til at tekstkunnskap har blitt eit tungt emne i norskfaget. Døme på det er at i rammeplanen for allmennlærarutdanninga i 1999 nytta ein omgrepet «tekst» i overskrifta til alle dei tre målområda (KUF, 1999), at i LK06 hadde tre av fire hovudområde i norskplanen omgrepet «tekst» i overskriftene (Rogne, 2008, s. 11) og at i L20 blir «tekst» nytta i overskriftene for tre av seks kjerneelement (UDIR, 2020, s. 2f).

Den historiske gjennomgangen syner at fagdidaktikken etter kvart vart eit dominerande emne i norskfaget i lærarutdanninga. Her skal me definere norskdidaktikken som lære om undervisning i norskfaget, samt innhaldselement som tek opp metaperspektiv på norskfaget (sjå Rogne, 2012, s. 59ff for ei utførleg 
drøfting av omgrepet). Eit poeng i denne samanhengen er å skilje læringsutbyte som tek opp reint faglege moment for studentane frå læringsutbyte som tek opp elevane sine møte med dei same momenta. Eit døme her kan vere eit skilje mellom det studentane skal lære i syntaks, og det at studentane kan bruke kunnskap om syntaks i skriveopplæringa til elevane. Både i skulen generelt òg i skulefaget norsk spesielt har lese- og skriveopplæringa vore heilt sentral (jf. Skjelbred 2010, s. 163f), så desse hovudemna er naturleg å skilje ut som eigne underkategoriar i norskdidaktikken.

Ein siste kategori som skal takast med her, er studentane si eigenutvikling. Historisk har me eit klart skilje med kravet om artium frå 1973. Før det vart studentane si eigenutvikling i skriftleg og munnleg framstilling mykje vektlagt. Seinare har dette blitt tona ned, ut i frå føresetnaden om at dette vart utvikla i vidaregåande skule. Noko har det likevel vore, og det er særleg interessant å sjå om omlegginga til forskingsbasert masterutdanning fører til endringar (jf. Rogne \& Munthe, 2017, s. 77f).

Dermed ender me opp med kategoriane språkkunnskap, litteraturkunnskap, tekstkunnskap, fagdidaktikk og studentane si eigenutvikling. Ei slik kategorisering kan vere problematisk, særleg i ein didaktisk samanheng, fordi ein kan risikere å fokusere på enkeltaspekt framfor samanhengar i faget (jf. Ongstad, 2004, s. 100f). I ei norsklærarutdanning vil det òg gjelde samanhengen mellom disiplinær og fagdidaktisk kunnskap, fordi dei vil vere komplementære (jf. Osdal \& Madssen, 2014, s. 3). Faglege samanhengar mellom innhaldselement gjer òg at kategoriane kan diskuterast, t.d. at tekstgrammatikk og litterære tekstar hamnar under høvesvis språk og litteratur, og ikkje under tekst. Vidare at munnleg ikkje er ein eigen kategori, men blir plassert under andre (som talemål under språk, drama under litteratur, munnlege tekstar under tekst, og munnleg rettleiing under fagdidaktikk).

Når valet likevel fall på å dele inn i desse fem kategoriane, var det særleg med omsyn til at dei gjer det lettare å få systematisk oversyn over fagelementa. Dessutan får ein synleggjort tilhøvet mellom dei over tid, og dermed vil ein kunne peike på sentrale faglege utviklingstendensar. Diskusjonar kring fagleg kategorisering og vektlegging kan òg seiast å vere eit vitaliserande element i fagdidaktikken, sidan den opphavlege vitskaplege bakgrunnen til deltakarane ofte vil kunne farge standpunkta deira. Slik sett er det på sin plass å seie frå at artikkelforfattaren har bakgrunn frå nordisk språkvitskap, men har seinare gått meir i retning lesevitskap/tekstvitskap og norskdidaktikk.

\section{Materiale og metode}

Hovudmaterialet i undersøkinga består av fire dokument, dvs. norskdelen av dei nasjonale retningslinjene for grunnskulelærarutdanningane for både 1-7 og 5-10 etter reformene i 2010 (KD, 2010b og KD, 2010c) og 2016 (UHR, 2016a og URH, 
2016b). Både statusen og ansvaret for utvikling av desse dokumenta har endra seg i perioden. For alle desse utdanningane har det juridisk forpliktande dokumentet vore rammeplanen, som har forskriftsstatus. I 2010 står det at retningslinjene er heimla i forskrifta, og vidare at dei er «[...] utfyllende i forhold til forskriften og skal være førende for institusjonenes programplaner». (KD, 2010b, s. 6). Ansvaret for retningslinjene låg til Kunnskapsdepartementet, som let rammeplanutvalet styre faggrupper som stod for skrivinga. I 2014 vart ansvaret for retningslinjene overført til Universitets- og høgskolerådet (UHR), Nasjonalt råd for lærarutdanning (no UHR-Lærarutdanning), som har hatt ansvaret for 2016retningslinjene. Her heiter det at retningslinjene skal «[...] gi forpliktende kvalitetsstandarder for god lærerutdanning og skal revideres i tråd med kunnskapsfeltets utvikling.» (UHR, 2016a, s. 2) I eit lengre historisk løp ser ein altså at innhaldssida i norskfaget har gått frå å vere lovfesta til å vere forskriftsfesta, så forskriftsfesta gjennom rammeplan, etterpå heimla i forskrift, før ein ved den siste reforma flyttar ansvaret frå det politiske (ved departementet) til institusjonane (ved UHR).

Ein går altså frå det ein kan kalle statspedagogiske normtekstar som fungerer som bindeledd mellom politikk og lærarutdanning (Karseth \& Sivesind, 2009; Madssen, 1999) til fellesinstitusjonelle normtekstar, som kan seiast å ha lågare grad av direkte politisk styring og meir av fagleg styring og påverknad (Rogne \& Munthe, 2017). Styrken med normtekstundersøkingar er at ein får fram sider ved det intenderte norskfaget i lærarutdanningane (formuleringsarenaen), medan svakheitene er at ein ikkje får fram noko om det implementerte faget (realiseringsarenaen) (jf. Rogne 2012, s. 69f). Institusjonane lagar eigne programplanar med utgangspunkt i dei nasjonale retningslinjene. Ei undersøking knytt til 2010-reforma, der ein granska fem lærarutdanningsinstitusjonar, synte at institusjonane stort sett [...] har brukt mykje dei same læringsutbyteformuleringane som i dei nasjonale retningslinene, utan vesentlege endringar.» (Osdal \& Madssen, 2014, s. 5) Ein kan difor gå ut ifrå at retningslinjene vanlegvis er viktige for programarbeidet lokalt ved institusjonane.

Eit sentralt atterhald ved resultata er likevel knytt til at dei berre gjeld formuleringsarenaen, og at fagutviklinga i lærarutdanningane kan vere påverka av mange andre faktorar lokalt. Her kan til dømes studentane si rolle nemnast, pensumlitteraturen, eksamensordningane, klasseromssituasjonen (t.d. digitale verktøy), institusjonelle satsingsområde og dei tilsette sin bakgrunn og interessefelt. Til det siste kan ein for eksempel peike på tradisjonen ved mange av utdanningane for å dele faget $\mathrm{i}$ ein språkdel og ein litteraturdel, òg ved stillingsutlysingar (jf. Osdal \& Madssen, 2014, s. 3). Dette kan gjere at ein vektlegg læringsutbyte-formuleringane frå nasjonale retningslinjer ulikt.

Den metodiske framgangsmåten i møte med materialet kan karakteriserast som hermeneutisk, med innhaldsanalyse av normtekstar basert på nærlesing (Selander, 2010; Rogne, 2012, s. 76ff). Vidare er metoden komparativ, med samanlikning av tekstane for å syne diakron utvikling frå 2010 til 2016. 
Forskingsspørsmålet har vore: Kva for faglege utviklingstrekk finn ein i norskfagets læringsutbyteformuleringar i grunnskulelærarutdanningane frå 2010 til 2016? Analysane er avgrensa til læringsutbyteformuleringane, fordi det er desse som blir mest nytta i det daglege undervisningsarbeidet ved institusjonane. Dei innleiande delane av retningslinjene kjem gjerne i bakgrunnen, noko ein t.d. ser ved eksamensarbeid, der ein ofte i t.d. sensurrettleiingar berre viser til konkrete læringsutbyte som skal testast. Ei tilsvarande utvikling ser ein i grunnskulen, både ved eksamenar og i lærebøker - her òg viser ein til konkrete kompetansemål frå læreplanen ved oppgåver og innleiingar til kapittel.

Læringsutbyteformuleringane har eg i størst mogleg grad brote ned til einskilde omgrep, der innhaldsida er den viktige. Retningslinjene sine skilje mellom «kunnskap» «ferdigheit» og «generell kompetanse» har eg sett vekk frå i analysearbeidet. Grunnen til det er at den interne samanhengen mellom desse verka å vere lite vektlagt i arbeidet med å utarbeide retningslinjene. Eit sentralt prinsipp ser heller ut til å ha vore at eit innhaldselement må «kome med», framfor at det er sett i ein samanheng med kunnskapar og ferdigheiter. Slik kan ein òg få plass til meir av dei faglege elementa ein vil ha med, all den tid komiteane har vore pålagt å halde seg innanfor eit avgrensa tal på læringsutbyte. Eit døme kan vere 5-10-retningslinjene frå 2010, der studentane skal utvikle ferdigheiter i å vurdere ulike typar norskfaglege læremiddel, medan det ikkje er noko under «kunnskapar» om dei same læremidla (KD, 2010c, s. 29ff). A vurdere noko utan kunnskapar på fagområdet vil sjølvsagt vere vanskeleg.

Dersom ei læringsutbyteformulering inneheldt fleire innhaldselement, vart desse skilt frå kvarandre i vidare analyse. I t.d. formuleringa «har brei kunnskap om språket som system og språket i bruk» (KD, 2010c, s. 29) fekk ein då to innhaldselement: «språket som system» og «språket i bruk». Det blir vidare tatt noko omsyn til vektlegging i analysane, altså om studentane berre skal ha «kunnskap» om eit fenomen, eller om dei skal ha «brei» kunnskap osv. Innhaldselementa vart deretter sett opp i enkle tabellar, for å lette komparasjonen. Desse tabellane vart strukturert etter hovudkategoriane som vart utvikla frå den historiske gjennomgangen og omgrepsdrøftingane. Eit døme på ein slik tabell er lagt ved til slutt (Vedlegg 1) for å synleggjere framgangsmåten.

Her må det likevel takast eit atterhald knytt til metoden og skrivemåten i artikkelen. Når eg til dømes skriv at dialektar er ute av retningslinjene i 2016, så betyr det berre at omgrepet ikkje er nemnt. Ein kan godt undervise i dialektar under andre emne, som «munnleg kommunikasjon», og fleire fagfolk ved institusjonane vil truleg halde fram å undervise i dialektar utan at det står i dei nasjonale retningslinjene. Ei slik utelating av omgrep/emne er etter mitt syn interessant uavhengig av dette, fordi slike tekstlege val i retningslinjene kan seie noko om fagutvikling på eit overordna plan, altså knytt til det «intenderte» norskfaget. Ein kan til dømes òg tenkje seg at nytilsette ved institusjonane, som ikkje er sosialisert inn i fagtradisjonane i same grad, i større grad les konkret kva som står i retningslinjene. 


\section{Analysar}

\section{1-7}

Innafor språkkunnskap i 2010-retningslinjene for Norsk 1 (30 sp, obligatorisk) fann ein barns språkutvikling, språket som system og i bruk, talemålsvariasjon, skriftspråksnormering, fleirspråklegheit, norsk som andrespråk og retorikk. 2016 går talemålsvariasjon, skriftspråknormering og retorikk ut, medan språkleg identitet og språkvanskar kjem inn. Ein ser altså emne med lang fartstid i faget forsvinn ut av den obligatoriske delen, medan emne med meir individuell vinkling står noko sterkare.

I litteraturkunnskap frå 2010 la ein vekt på litteraturteori, barnelitteratur, nyare litteratur for ungdom og vaksne, litterære samtalar, litteraturformidling og litterær identitet. I 2016 er vekta på eit utval skjønnlitterære tekstar for barn og unge i ulike sjangrar og medium. Emnet blir altså noko nedprioritert, og særleg interessant er det at vaksenlitteraturen er ute for desse studentane. Ein tek òg bort teoretiske vinklingar og ulike typar formidling og identitet.

Når det gjeld tekstkunnskap, er det ein endå kraftigare reduksjon. I 2010 fann ein her munnlege, skriftlege, samansette og digitale tekstar, fiksjonstekstar og sakprosa, frå tradisjonelle og moderne medium, tekstkvalitet, teksttypar, tekstkunnskap, ulike bruksområde, samt danske, svenske, samiske og utanlandske tekstar i omsetjing. Sju år seinare er det berre munnlege, skriftlege, multimodale i tekstar i ulike sjangrar og medium igjen. Dessutan har ein tatt inn tekstar på bokmål og nynorsk. Samiske, utanlandske og nabospråkstekstar er borte, i lag med digitale tekstar. Det same er arbeid med teksttypar, kvalitet, bruksområde m.m.

Under leseopplæringa i fagdidaktikken var lese-/leseopplæringsteoriar, strategiar, utvikling, metodar, kartlegging, vanskar og leselyst dei viktige punkta i 2010. I 2016 har ein tatt ut teori-formuleringane, strategiar, utvikling og leselyst. Inn har eit skilje mellom den første leseopplæringa og lesing på mellomsteget kome, samt tilpassing av leseopplæring og vurdering av leseferdigheiter. Eit tilsvarande mønster ser ein i skriveopplæringa: Teoriar, strategiar og utvikling forsvinn ut, medan dei same momenta kjem inn på skrivesida som på lesesida. I tillegg har ein fjerna sjangerskriving, i ulike medium, elevtekstperspektiv, skape og vurdere samansette og digitale tekstar, og skriveopplæring på bokmål og nynorsk.

Andre fagdidaktiske moment som går ut, er å stimulere elevars estetiske sans, styrke identiteten deira og oppmode til deltaking i det offentlege livet, samt tverrfagleg arbeid. Inn kjem kartleggingsprøver og nasjonale prøver, læringsfremjande respons og elev- og klassesamtalar. Her er òg eit punkt om å undervise i begge målformer, og det verkar å kompensere for at det har gått ut av skriveopplæringa. Ein legg altså opp til ei noko breiare tilnærming på det punktet. Elles er det verdt å merkje seg at teoretiske tilnærmingar generelt er svekt, ein 
legg mindre vekt på samansette og digitale tekstar og at kunnskap om kartleggingsprøver og nasjonale prøver kjem tyngre inn i norskfaget. Punkta med elevsamtalar og klassesamtalar er kanskje meir overraskande, sidan dei er så generelle at dei vanlegvis ville ha vore plassert i faget pedagogikk og elevkunnskap og ikkje i norskfaget.

I 2010 var eigenutviklingskrav sikker munnleg språkbruk, kritisk og konstruktiv fagleg refleksjon og at studentane var støe i skriftleg bokmål og nynorsk. I 2016 er dei to første borte, medan kravet til skriftleg bokmål og nynorsk har blitt «å meistre». I tillegg har det kome inn eit krav til å vurdere eigen praksis. Dei språklege krava til studentane har altså blitt klart svekte.

Dersom ein går over til det valfrie Norsk 2 (fordjuping 30 sp), finn ein i 2010 ei vektlegging av språklege endringsprosessar, normeringsspørsmål, dialektar og språkleg kommunikasjon i ulike medium. I 2016 kjem mange nye moment inn språkleg variasjon, norsk som andrespråk, språkhistorie, normering i bokmål og nynorsk, grammatikk- og språkkunnskap i analyse, faghistorie med språkleg tilnærming og munnleg kommunikasjon. Ein får òg samisk språk, nasjonale minoritetsspråk og nabospråk. Ut forsvinn dialektar og ulike medium. Ein får altså ei klar styrking av språkkunnskap i Norsk 2, og fleire av emna som forsvann ut i Norsk 1, kjem inn igjen her.

Under litteraturkunnskap måtte studentane etter 2010-retningslinjene ha litteraturhistorisk oversyn, kunnskap om sentrale verk i norsk fiksjonslitteratur og adaptasjon av barnelitterære tekstar, samt å kunne sjå sentrale norske tekstar i lys av nordisk og annan internasjonal litteratur. Sju år seinare er det berre litteraturhistorie igjen, og elles legg ein vekt på samisk litteratur, skjønnlitteratur frå ulike tider og for barn, unge og vaksne, litteraturteoretiske perspektiv, litteraturkunnskap i analyse, skjønnlitteratur i tradisjonelle og moderne medium og norskfaget som historisk litteraturfag. Her ser ein at kanontenkinga («sentrale») går ut, medan ein del av punkta som vart fjerna i Norsk 1, kjem inn igjen. Nordiske og internasjonale perspektiv er heilt ute.

Munnlege og skriftlege sjangrar, sentrale verk i norsk sakprosa, samansette tekstar, tekstar skrivne for barn og sentrale norske tekstar i historisk samanheng var tema knytt til tekstkunnskap i 2010. Desse har blitt til analyse av munnlege, skriftlege og multimodale tekstar, og sakprega tekstar i tradisjonelle og moderne medium i 2016. Ein ser, som i litteraturkunnskap, at «sentrale» går ut til fordel for analytisk tilnærming. Tekstar for barn og det historiske er òg ute. Dessutan har «sakprosa» blitt til «sakprega».

Innanfor leseopplæringa i fagdidaktikken fann ein teoriar om den andre leseopplæringa, lesing i kulturen, tilpassa leseopplæring for 1-7 og norsk som andrespråk, leserettleiing og leseprøver i 2010. I 2016 er punkta opplæring og ulike metodar i vidare leseopplæring og tilrettelegging for lesing av saktekstar og skjønnlitteratur i ulike sjangrar og medium. Tilsvarande utvikling er det for skriveopplæringa. Interessante poeng er at teoriar forsvinn ut og metodar kjem 
inn, samt at emne som kom inn andre stader, t.d. norsk som andrespråk under språk, går ut her. Vidare er medieperspektivet styrkt her òg.

Andre fagdidaktiske moment i 2010 var innsikt i og rettleiing av elevars tekstarbeid, tilrettelegging for munnleg språkutvikling, forskingsbasert innsikt i norskfaget, faghistorie, elev-elevsamtalar og elev-lærarsamtalar. I 2016 er det berre faghistorie og norskdidaktisk FoU igjen. Nye emne er litteraturdidaktiske tilnærmingar, begynnaropplæring, tilpassa opplæring for minoritetselevar, å formidle fagstoff, samt fagleg og tverrfagleg samarbeid. Ein ser altså ei styrking av begynnaropplæring og minoritetsperspektiv, medan det munnlege og dei noko meir pedagogisk orienterte samtalene går ut.

Studentane si eigenutvikling var knytt til kritisk refleksjon rundt norskfaget i historisk perspektiv og vurdering av eigen praksis i 2010. Desse punkta er ute i 2016, og ein får i staden to forskingsorienterte punkt - å skrive akademiske fagtekstar på bokmål og nynorsk og å drøfte forskingsetiske problemstillingar. Slik får ein òg ei styrking av skriveferdigheitene i dei to målformene som vart svekt i Norsk 1, men då berre for dei som vel fordjuping i faget (Norsk 2).

\section{5-10}

Sidan både Norsk 1 og Norsk 2 (60 stp. til saman) er obligatorisk når du vel norsk som fag i 5-10-utdanninga, er det mest føremålstenleg å sjå desse under eitt i dei ulike kategoriane.

Sentrale språklege emne i 2010 var barns og unges språkutvikling, språket som system og i bruk, nabospråk, samisk, nasjonale minoritetsspråk, fleirspråklegheit, norsk som andrespråk, retorikk, språklege endringsprosessar, talemålsvariasjon og dialektar, språkhistorie etter 1800, normering, ungdomsspråk og språkleg kommunikasjon i ulike medium. I 2016 kom språkleg identitet, analyse av språk/språkbruk og munnleg kommunikasjon inn, medan emne som barns og unges språkutvikling, ungdomsspråk, retorikk og talemålsvariasjon/dialektar går ut. Her er det verdt å merkje seg at aldersspesifikke tilnærmingar no er dempa, og at tradisjonelle emne som dialektar og retorikk er ute av retningslinjene. Dei siste ser ut til å bli er erstatta av det noko breiare «munnleg kommunikasjon» og analyse av språkbruk.

Litterære emne i 2010 var særleg litteraturteori, litteratur for barn, unge og vaksne, lese eit breitt utval litteratur og sentrale verk i norsk fiksjonslitteratur, litterære samtalar, litteraturhistorisk oversyn, adaptasjon av barnelitterære tekstar og å sjå sentrale norske tekstar i lys av nordisk og internasjonal litteratur. Mykje av dette går igjen i 2016, men formuleringar som «breitt og sentralt» er ute. Det same er litterære samtalar, adaptasjon og komparative perspektiv. Inn kjem samisk litteratur, vekt på sjangrar og medium, samt multimodal litteratur. Ein kan merkje seg at det historiske framleis står like sterkt, at teoretiske tilnærmingar blir noko dempa og at nordisk/internasjonal litteratur går ut. Det at formuleringar knytt til «sentrale verk» går ut, fører til ei svekking av litterær kanontenking i planen. 
Teksttilnærmingane i 2010 var knytte til munnlege, skriftlege og samansette tekstar i ulike medium. Desse er òg med i 2016, men ei rekkje andre punkt er kutta ut: digitale tekstar, munnlege og skriftlege sjangrar, sentrale verk i norsk sakprosa, tekstadaptasjon, tekstsamanlikning unge-vaksne og sentrale tekstar i historisk samanheng samanlikna med nordiske og internasjonale. Ein ser altså ei klar svekking av vekta på tekstkunnskap - ungdomsperspektivet forsvinn, det same gjer historiske og komparative perspektiv.

Leseopplæringa i fagdidaktikken var 2010 knytt til teoriar, strategiar, utvikling, kartlegging, vanskar, leselyst, motivering, leseforståing, lesing i kulturen og norsk som andrespråk. I 2016 var teoriane og strategiane tekne ut, i lag med leselyst og motivasjon, lesing i kulturen og norsk som andrespråk. Inn kjem vekt på ny teknologi, tilpassa opplæring, mellomsteget og lesing av saktekst, ulike sjangrar og medium. Tilsvarande for skriveopplæringa så er teoriar, strategiar og norsk som andrespråk fjerna, men òg skriftforming, bokmål/nynorsk, ei rekkje elevteksttilnærmingar, samansett/digital tekstproduksjon, argumenterande skriving og skriving, og det å bruke kunnskap om talemål og normering i skriveopplæringa. Inn kjem dei same elementa som i lesing, sidan lesing og skriving stort sett er formulert i fellespunkt. Ein ser at fleire punkt som hadde tekstperspektiv i den førre planen, som sjangrar og digitale tekstar, her kjem inn i eit lese/-skriveperspektiv i staden. Det er òg verdt å merkje seg at vektlegging av teoriar blir svekt her òg, samt at tilnærmingar som går på leselyst og motivasjon går ut.

Vidare finn ein ei rekkje andre fagdidaktiske punkt i 2010. Det var litteraturdidaktikk, mange punkt knytt til munnleg opplæring, læreplan, norskundervisning på ulike trinn, vurderingsmetodar, læremiddel, digitale verktøy, stimulering av elevars estetiske sans og styrking av identiteten deira, tverrfagleg arbeid, oppmoding til deltaking i offentleg liv og å sjå opplæringa som ein del av eit aktivt deltakardemokrati, sidemål, forskingsbasert innsikt i norskfaget, faghistorie og å sjå faget i eit danningsperspektiv. I 2016 blir læreplan svekt, medan det estetiske og demokratiperspektivet går ut. Dessutan får munnleg opplæring færre punkt. Inn kjem nasjonale prøver, elev- og klassesamtalar, vekt på mellomsteget, planlegging, gjennomføring og refleksjon over norskundervisning, gjere greie for fagdidaktiske val og gjere fagleg utviklingsarbeid. Sentrale endringar er altså at læreplanar blir svekt medan nasjonale prøver kjem inn, ein får meir vekt på generelle pedagogiske emne som elev- og klassesamtalar og demokratiske element blir dempa. Punkt knytt til estetisk sans og identitet er ikkje lenger med i 2016.

Når det gjaldt studentars eigenutvikling i 2010, la ein vekt på at studentane skulle vere sikre i munnleg språkbruk, støe skriftleg i bokmål og nynorsk, kritiske og konstruktive i fagleg refleksjon og i stand til å vurdere eigen praksis. I 2016 kjem forskingsetiske problemstillingar og akademiske fagtekstar på bokmål og nynorsk inn, men krav til det munnlege forsvinn ut. Dermed får ein noko sterkare krav til forskingstilnærmingar for studentane i dei nyaste retningslinjene for 5-10. 


\section{Drøfting}

Ut frå analysane kan ein lese fire generelle utviklingstendensar i dei nasjonale retningslinjene for norskfaget i grunnskulelærarutdanningane. Tendensane er identifisert ut frå eit krav om at dei må vere representerte i minst to av analysekategoriane. Dei faglege kategoriane og tilhøvet mellom dei vil bli drøfta etterpå. I tendensane ser me ei styrking av eitt felt, og tre andre som blir svekte:

\section{Historiske tilnærmingar blir styrkt}

I 2003-planen var faghistorie det einaste historiske emnet som var igjen i norskplanen, men i 2010 kom både språk- og litteraturhistorie inn igjen på 5-10programmet, og litteraturhistorie kom inn på valfrie Norsk 2 på 1-7. Desse held seg i 2016, og dessutan kom språkhistorie no òg inn på Norsk 2. Faghistorie har vore inne på 5-10 og Norsk 2 gjennom begge dei siste reformene. Det einaste historiske emnet som har vorte svekt, er det å sjå tekstar i historisk samanheng. Det kom inn på 5-10 i 2010 og forsvann ut i igjen i 2016, men det kan òg sjåast i samanheng med ei generell svekking av tekstkunnskap som emne i denne planen.

Med Stian Hårstad (2016) kan me seie at norskfaget har hatt ein historiserande dimensjon heilt frå etableringa av faget på 1800-talet. Han peikar på at vitskapsfilosofisk var den tyske historismen ein viktig del av idégrunnlaget, og at den historiske betraktningsmåten etter kvart vart [...] normen for alle human- og samfunnsvitenskaper i Europa, og dermed skulle alle begivenheter og forhold forstås som ledd i et historisk forløp» (Hårstad, 2016, s. 2). I morsmålsfaget var litteraturhistorie særleg viktig i byrjinga, men språkhistorie vart òg tematisert allereie for 150 år sidan (sst., Aase, 2002, s. 95). Desse historiske emna har vore med i norskfaget i skulen heile vegen, men med noko ulik vekt - t.d. såg ein ei svekking i 70-åra, før dei vart styrkt igjen dei neste tiåra (jf. Nordstoga, 1998, s. 11f; Hårstad, 2016 s. 5ff). Slik sett kan me seie at norskfaget i skulen og grunnskulelærarutdanningane har vore noko i utakt på dette feltet, med fjerninga av språk- og litteraturhistorie i 2003-planen for allmennlærarutdanninga som det mest slåande dømet.

\section{Teoretiske tilnærmingar svekt}

Heilt sidan lærarutdanningane vart pedagogiske høgskular frå 1974 har ulike teoretiske tilnærmingar vore med i fagplanane for norskfaget (NOU, 1974; KUD, 1980; Lærarutdanningsrådet, 1986²; KUF, 1994; KUF 1999; UFD, 2003). I retningslinjene for 2010 finn ein t.d. leseteoriar, leseopplæringsteoriar, skriveopplæringsteoriar, norskdidaktiske teoriar, teoriar om munnleg opplæring og teoriar om samansette tekstar. Seks år seinare er alle desse borte. Dessutan er litteraturteori fjerna frå den obligatoriske delen av 1-7-utdanninga, og innslaget av litteraturteori er dempa på 5-10. Før 2010 var teoriar om språkutvikling,

\footnotetext{
${ }^{2}$ Denne planen kom aldri i bruk på grunn av eit regjeringsskifte.
} 
språklæring o.l. og med i planane, men desse forsvann ut med denne planen, og det i ein plan som elles la mykje vekt på teoretiske tilnærmingar.

I og med at teoretiske tilnærmingar gjerne er knytt til akademisk nivå, og ein såg ei styrking av slike tilnærmingar når lærarskulane vart pedagogiske høgskular, er det noko overraskande at slike tilnærmingar nærmast forsvinn i norskfaget når ein går over til masterutdanning og sterkare krav til forskingsbasering med 2016retningslinjene. Ei forklaring kan vere at ein reknar akademiseringa av utdanningane for å ha kome så langt at det ikkje er nødvendig å nemne teoriar eksplisitt. Ein del av lærebøkene som blir brukte i utdanningane, legg til dømes mykje vekt på teori: Teorier om tekst i møte med skolens lese- og skrivepraksiser (Matre, Sjøhelle og Solheim, 2012), A tenke teori. Om leseteorier og lesing (Aamotsbakken \& Knudsen, 2011) og Skrivepedagogikk. Teori og metode (Eritsland, 2007). Men dersom ein ser på overordna dokument som rammeplanen, finn ein læringsutbyteformuleringar som «kandidaten har inngående kunnskap om relevant forskning og teori $[. .] ».(\mathrm{KD}, 2016 \mathrm{a})$. Det same ser ein i innleiingane til dei nasjonale retningslinjene, der særleg vitskapsteori og progresjon i opplæringa knytt til denne, står sentralt (UHR 2016b). No er ikkje generell vitskapsteori og faglege teoriar nødvendigvis det same, men krava til progresjon og behovet for spesifikk fagleg teoretisk forståing, òg med tanke på FoU- og masteroppgåve, gjer det viktig med slike tilnærmingar på alle nivå i utdanninga.

Krava til meir djupnelæring i skulefaget norsk peikar i den same retninga - dei vil stille større krav til teoretiske kunnskapar frå lærarane. Til dømes argumenterer Tor Arne Haugen for potensialet funksjonell grammatikk har for djupnelæring, og han peikar på at kjenneteikna på djupnelæring mellom anna er at elevane «[...] integrerer kunnskap i heilskaplege konseptuelle system», og at dei «[...] ser etter mønster og underliggjande prinsipp» (Haugen, 2019, s. 14). Både konseptuelle system, mønster og underliggjande prinsipp kan knytast til evna med å forstå, formidle og utvikle faglege teoriar.

\section{Internasjonale perspektiv går ut}

Krav om lesing av omsette tekstar frå andre land enn dei nordiske har variert noko opp igjennom tidene i lærarutdanninga. Ein fann til dømes krav til «nokre prøver av verdsbokheimen» i 1939-planen (Lærarskulen, 1939, s. 72) og ei formulering om at ikkje-skandinavisk litteratur kunne veljast av elevane i 1965-planen (KUD, 1965, s. 16). Så fann ein lite av det fram til 1999-planen, då studentane skulle lese nokre tekstar frå andre kulturar (KUF, 1999, s. 15). I 2003 var det krav om å kunne analysere og tolke tekstar frå andre språkområde (UFD, 2003, s. 27). Retningslinjene frå 2010 inneheldt, som me har sett, krav til komparasjon med utanlandske tekstar, både under tekstkunnskap og litteratur. Desse krava forsvinn i 2016, i lag med krava om å lese danske og svenske tekstar - som stort sett har vore ein del av norskfaget i lærarutdanninga så lenge faget har eksistert. Igjen står berre nabospråksundervisning og samiske tekstar. 
Dette står då i noko kontrast til norskfaget i skulen, der elevane t.d. på 8.-10. trinn skal «gjengi innholdet og finne tema i et utvalg tekster på svensk og dansk» og «gi eksempler på og kommentere hvordan samfunnsforhold, verdier og tenkemåter framstilles i oversatte tekster fra samisk og andre språk» (UDIR, 2013, s. 9). I innleiingsdelane til LK06 og LK06-13 og L20 kan ein likevel sjå litt av den same tendensen, med ei demping av internasjonale perspektiv for norskfaget i skulen (UDIR, 2006, s. 2; UDIR, 2013, s. 2; UDIR, 2020, s. 2). Kontrasten verkar endå større mot høgare utdanning generelt, og lærarutdanning spesielt, der ein har satsa mykje på internasjonalisering dei siste åra. Krava til å ha med internasjonale perspektiv og dimensjonar var t.d. klart til stades i rammeplanen for grunnskulelærarutdanningane i 2010, og fleire av institusjonane la vekt på å arbeide med «internasjonalisering hjemme» (Følgjegruppa, 2011, s. 75f). Men for norskfaget sin del var ikkje denne arbeidsmåten utbreidd blant dei fem institusjonane som Følgjegruppa undersøkte: «Når det gjeld primær- eller skjønnlitteraturen, er det få døme på ikkje-norske tekstar.» (Osdal \& Madssen, 2014, s. 13)

Dei internasjonale perspektiva er òg tydeleg til stades i rammeplanen frå 2016, der det mellom anna heiter at «Kandidaten kan styrke internasjonale og flerkulturelle perspektiver ved skolens arbeid» (KD, 2016a, §2). Forklaringa på at ein tek ut omsett internasjonal litteratur frå dei nasjonale retningslinjene $\mathrm{i}$ norskfaget ser altså ikkje ut til å liggje korkje i ein sjølvsagt innarbeidd praksis eller endringar i overordna styringsdokument.

\section{Svekking av tradisjonelle norskfaglege emne}

Heilt sidan 1890-talet har dei norske dialektane vore ein viktig del av norskfaget i lærarutdanningane (Norsk Lovtidende, 1891, s. 170), med eit unntak for den minimalistiske 2003-planen, der ein berre krev generell innsikt i språkvariasjon, og ikkje spesifikt nemner dialektar eller målførekunnskap (UFD, 2003, s. 28). I 2010-retningslinjene er talemålsvariasjon og dialektar emne som er godt representerte, men i 2016 er dei heilt ute, medan det generelle «munnleg kommunikasjon» ser ut til å kome inn som erstatning. Dette gjeld òg fordjupinga på 1-7. Her er det altså tale om eit tradisjonsbrot, som kan få konsekvensar utover norskfaget. I tillegg til den reint lingvistiske innsikta slik undervisning kan gi, og gevinstane i møte med språkhistorie, normering og skriveopplæring på bokmål og nynorsk, har dialektane hatt ei rolle i norsk lærarutdanning og skule som er unik i internasjonal samanheng. Sidan 1878 har lærarane etter lova måtte tilpasse talemålet sitt til elevane, i motsetnad til mange andre land, der elevane må lære seg det normaliserte, hovudstadsbaserte standardtalemålet som læraren nyttar (jf. Jahr, 1984, s. 474ff). Denne norske modellen kan verke både demokratiserande og dannande i skulen, og mangfaldstankegangen som ligg bak, kan òg vise veg framover, som t.d. Pål Hamre har peikt på: «Både språkleg og kulturelt kan ein seie at skulen generelt og norskfaget spesielt representerer eit tilkjempa mangfald 
som i seg sjølv er ein ressurs når skulen blir meir fleirkulturell og fleirspråkleg.» (Hamre, 2017, s. 37)

Til dette kjem det at dialekt/talemålskunnskap har eigne kompetansemål i norskfaget både på barne- og ungdomstrinnet (UDIR, 2013, s. 8f). Dessutan forsvinn òg krava til studentane si eigenutvikling i munnleg språkbruk i 2016retningslinjene for norskfaget, og det er òg eit brot med ein lang tradisjon i lærarutdanningane. Det at lærarane er i stand til å drive god munnleg modellering for elevane, kan ha positiv effekt på læringa til elevane (jf. Bakke \& Kverndokken, 2014, s. 61ff). Behandlinga av retorikken som fagemne peikar òg mot ei svekking av det munnlege i lærarutdanningane i det siste. Retorikken, som vart fagemne i norskfaget i vidaregåande skule med LK06, i ungdomsskulen med LK06-13 (jf. Eide, 2017, s. 59f) og vidareført i L20 (UDIR, 2020), kom òg inn i dei nasjonale retningslinjene for norskfaget i lærarutdanningane i 2010. I 2016 forsvinn emnet ut i igjen, utan at det lett å sjå noko forklaring ut over presset på reduksjon av læringsutbyte.

Eit anna tradisjonelt emne som ser ut til å vere på retrett, er litteratur for vaksne. Heile vegen frå 1891 til 2010 har det vore eksplisitte mål for slik lesing, igjen med eit unntak for 2003-planen. I 1891 nemner ein spesielt Holberg, Wergeland, Bjørnson og Ibsen (Statsseminarier, 1891, s. 16) og i 2010 står det at studentane skal ha «kunnskap om litteratur frå nyare tid som rettar seg mot ungdom og vaksne lesarar» (KD, 2010b, s. 30). For det obligatoriske 1-7norskfaget i 2016 er ikkje vaksenlitteraturen nemnt spesifikt, medan han blir det på det valfrie Norsk 2 og på 5-10-utdanninga. I det obligatoriske norskfaget skal vekta leggjast på «litteratur for barn og unge» (UHR, 2016a, s. 28), og det kan sjåast på som eit resultat av didaktiseringa av faget dei siste tiåra. Ein innrettar utdanninga meir spesifikt mot skulen, medan eigenutviklinga til studentane blir tona ned. Ei slik eigenutvikling var svært tydeleg til stades i tidlegare planar: I 1980 måtte studiet til dømes femne om sider ved norskfaget som «[...] er viktige for den personlege og faglege utviklinga til studentane [...]» og ein hadde mål som «å utvikle studentane som lesarar og språkbrukarar» (KUD, 1980, s. 55). I 1992 finn ein formuleringar som «Å bli norsklærer må dreie seg om en prosess der studenten får personlig utbytte av faget og modnes [...]» (KUF, 1994, s. 252). I den delen av lærarutdanningane der norskfaget er under sterkast press pga. emnetrengsel, er det altså slike perspektiv som blir svekte.

\section{Utviklinga i og mellom dei faglege kategoriane}

Her vil først eitt karakteristisk utviklingtrekk frå kvar av dei fem faglege kategoriane bli diskutert, før blikket blir retta mot tilhøvet mellom kategoriane. Når det gjeld språkkunnskap, kan det vere freistande å velje eit moment som peikar mot eit større poeng knytt til utviklinga av grunnskulelærarutdanningane. Det gjeld aldersspesifikke perspektiv, der ein i 2010 fann eit krav om at studentane «har kjennskap til språk som ungdom brukar» (KD, 2010c, s. 32). Dette er eit sosiolingvistisk emne som kan vere både fagleg og fagdidaktisk interessant for 
komande lærarar, men det har ikkje vore mykje vektlagt i lærarutdanningane tidlegare, i motsetnad til eit emne som barns språkutvikling - som har vore grundig behandla. Ein finn likevel eit døme i 1999-planen, der «barne- og ungdomsspråk» var valfritt emnestudium i Norsk 3 (KUF, 1999, s. 160). Temaet har heller ikkje vore grundig behandla i den sentrale pensumlitteraturen, sjølv om der finst døme på at det er omtalt (jf. t.d. Iversen, Otnes og Solem, 2004, s. 60f). Grunnen til at slike emne vart særleg aktuelle i 2010, var delinga av lærarutdanninga i to løp, 1-7 og 5-10, samt krav til differensiering mellom løpa som var nedfelte i rammeplanen. Krava til differensiering var eitt av punkta i 2010-reforma som institusjonane sleit med å følgje opp (jf. Følgjegruppa, 2015, s. 91), og det er difor litt overraskande at punkt som ungdomsspråk blir kutta ut. Mellomsteget er jo felles for dei to utdanningane, og kravet til differensiering gjeld enno (jf. UHR, 2016b, s. 6), og dermed er arbeid med ungdomsspråk nettopp ein norskfagleg måte å kunne møte slike krav på.

I litteraturkunnskap såg me at formuleringane om «sentrale verk» i norsk fiksjonslitteratur går ut i 2016-retningslinjene. Formuleringa «sentral» peikar mot ei kanon-tenking, sjølv om me ikkje har hatt kanon-lister med forfattarar og verk i lærarutdanningsplanane sidan før andre verdskrig (jf. Lærarskulen, 1939, s. 36). I skulen har skjønnlitteraturen dei siste tiåra gått frå svak styring (L97) til inga styring (LK06), medan ein til t.d. i Danmark har gått den andre vegen - frå inga styring til sterk styring (Vinje, 2005, 72f). Men sjølve tenkinga står enno sterkt blant t.d. elevane i vidaregåande skule, der ein del ser ut til å ha eit kulturkonservativt syn på verdien av kanonlitteratur og kulturarv (jf. Fodstad og Mortensvik, 2018, s. 18). Det same kan ein seie om ein del lærarar og læremiddelprodusentar (jf. Skau \& Blikstad-Balas, 2019, s. 98). Utviklinga i lærarutdanningane er likevel i tråd med utviklinga i skulen på dette punktet, og den kan òg kanskje forklarast med ei anna felles utvikling, nemleg bruk av målstyrte framfor innhaldsstyrte normtekstar. I skulen kan dette blant anna sjåast i samanheng med metodefridom for lærarane, medan det i høgare utdanning meir er knytt til internasjonal tilpassing til Bologna-prosessen (jf. Hamre, 2014, s. 465). Den direkte grunnen bak endringane frå 2010 til 2016 i lærarutdanningane ligg nok ikkje nødvendigvis her - dei kan heller sjåast som ein konsekvens av ei mykje meir varig tendens i norskfaget, der fjerninga av "sentrale verk» i noverande planar opnar for ein endå meir individualiserande praksis knytt til skjønnlitterær lesing.

Krava til tekstkunnskap er generelt svekte, men gitt den digitale utviklinga i dagens samfunn, er kanskje vekta på digitale tekstar det mest interessante. I 2010 skulle studentane både «[...] skape og vurdere digitale, samansette tekstar» (KD, 2010c, s. 31). 2016-retningslinjene er utan slike krav. Dei einaste gongane digitale tilnærmingar er nemnt her, er i samband med digitale læremiddel (UHR, 2016b, s. 58). Dermed kuttar ein for det første ut kravet til at studentane sjølve skal vere aktive digitale tekstskaparar. For det andre ser det ut til at digitale tekstperspektiv har blitt erstatta av arbeid i ulike «medium»(s.st.). No er gjerne nye medium 
digitale, men eit skifte mot arbeid med medium i staden for tekstar kan ha nokre implikasjonar. Éin kan vere at ein svekkjar samanhengane i faget, då nettopp tekstperspektiv kan sjåast på som det viktigaste samanbindande elementet i faget - altså kjernen i faget (jf. Aase, 2005, s. 70). Ein annan kan vere at det at ein enno ikkje er klar for å gjere faget fulldigitalt i alle skuleslag, og før det vil nettopp arbeid med digitale kontra tradisjonelle tekstar vere viktig for å utvikle tekstkompetanse. Til dette kjem òg tilnærmingar til adaptasjon, der tekstar kan vandre frå analoge til digitale medium og vice versa. I slike samanhengar er sjølvsagt òg medieperspektivet interessant, der særleg dei sterke òg svake sidene til ulike modalitetar realisert i ulike medium vil vere viktig. (Jf. Kress, 2003, s. 45). Fagleg sett kunne det difor vere ein ide å løfte fram både tekst- og medieperspektivet samstundes.

I fagdidaktikken ser me ei utvikling der arbeid med læreplanar blir svekt, medan nasjonale prøver kjem inn. Historisk har læreplanen for grunnskulen vore tematisert i planane for lærarutdanningane sidan 70-åra (NOU, 1974, s. 51). I 2010 hadde læreplanarbeid ein solid posisjon i læringsutbyta både for 1-7- og 510-utdanninga - ein kravde både kunnskap om gjeldande læreplan for skulen, evne til å bidra til lokal læreplanutvikling og bruk av læreplanen til å formulere undervisningsmål og evalueringskriterium (KD, 2010c, s. 30-32). I 2016-planane er det berre ei formulering knytt til generell kompetanse, der studentane skal vurdere eigen praksis med gjeldande læreplan som grunnlag (UHR, 2016b, s. 59). I staden har det kome ei ny læringsutbyteformulering der kandidaten skal ha kunnskap om nasjonale prøver (UHR, 2016b, s. 58). Dei nasjonale prøvene byggjer på dei grunnleggjande ferdigheitene i læreplanen (UDIR, 2019), som er tverrfaglege, og det er berre rekning og lesing på norsk og engelsk som blir testa. Der læreplanane syner eit breitt norskfag med vekt på kultur, identitet, kommunikasjon, skriveopplæring og aktiv deltaking i samfunnet, er altså dei faguavhengige nasjonale prøvene mykje smalare og utan eit spesifikt innhald bygd på norskfaglege kompetansemål. Dersom norskfaget i lærarutdanningane skulle utvikle seg i ei retning der ein legg meir vekt på fagleg sett snever testing og mindre på kultur og samfunnsdeltaking, kan ein risikere å undergrave sjølve fundamentet for det største skulefaget.

Under studentane si eigenutvikling ser me ei dreiing mot ei meir forskingsorientert tenking i læringsutbyta. I skriving kjem det i 2016 inn krav om at studentane skal kunne «skrive akademiske fagtekstar på nynorsk og bokmål» på 5-10 og Norsk 2 på 1-7, og krav til at dei skal kunne drøfte forskingsetiske problemstillingar (UHR 2016b, s. 60; UHR 2016a, s. 30). Denne styrkinga knytt til tekstproduksjon og refleksjon er logisk med tanke på omlegginga til masterutdanning, men det er samstundes viktig at dette blir følgt opp på kunnskapssida - der krava til forskingsbasert innsikt er noko svekt (jf. Rogne og Munthe, 2017, s. 73).

Når det gjeld tilhøvet mellom dei faglege kategoriane, så er krava til språkkunnskap om lag dei same i 2016 som i 2010, medan krava til 
litteraturkunnskap er litt svekte. Eit markant utviklingstrekk er at begge er svekte på Norsk 1, 1-7, men òg tilsvarande styrkte på det valfrie Norsk 2. Tekstkunnskapen, derimot, er klart nedprioritert overalt i dei nyaste retningslinjene. Dette samsvarar dårleg med utviklinga i skulen, der ein har gått den andre vegen frå 2006 til 2013 (jf. Rogne, 2017, s. 101). Vekta på fagdidaktikk, inkludert lese- og skriveopplæring, er så å seie uendra, og emnet held slik sett den sterke posisjonen sin. Studentane si eigenutvikling syner heller ikkje store endringar, og emnet kan ikkje seiast å ta stor plass i utdanningane. Her verkar det som ein set sin lit til at den vidaregåande skulen har utvikla elevane tilstrekkeleg, både når det gjeld allmenne skriveferdigheiter, munnleg framstillingsevne og personleg mogning. Dermed blir ein avhengig av eit godt søkjargrunnlag, dersom ein skal greie å få studentane gjennom ei masterutdanning med dei resultata samfunnet forventar.

Analysane har vidare vist eit anna utviklingsdrag som kan vere verdt å kommentere. Tidlegare har ein fått stadig større emnetrengsel i norskfaget, fordi nye emne som har kome inn, har vorte verande, medan få har gått ut. Utviklinga frå 2010-2016 syner eit meir ustabilt norskfag på den måten at mange emne går ut og mange kjem inn. Det gjeld alle dei undersøkte kategoriane. Ein del av forklaringa på dette kan liggje i at faggruppa som laga retningslinjene hadde ei «[...] eksplisitt forventning om reduksjon av antall læringsutbyttebeskrivelser fra Nasjonalt råd for lærerutdanning [...]» (UHR, 2019). Dermed måtte ein del ut. Samstundes skjer det mykje både i det norskdidaktiske forskingsfeltet og i skulen. Dermed måtte ein del inn. Tenkinga bak endringane har eg ikkje hatt høve til å undersøkje, men resultata syner i alle fall eit norskfag i stor endring.

\section{Avslutning}

Norskfaget i grunnskulelærarutdanningane utviklar seg i eit krysspress mellom eigne tradisjonar, forskingsutvikling, skuleutvikling og påverknad frå politiske aktørar. Historisk har faget vore styrt frå sentralt politisk hald, og som dei andre faga i utdanninga, med svært hyppige reformer. Lærarutdanningsreformene har kome langt oftare enn reformene i skulen, og dermed ofte i utakt med desse. Medan norskfaget held posisjonen sin som det største og viktigaste skulefaget, har faget gradvis mista den dominerande posisjonen i lærarutdanningane dei siste tiåra. Særleg tydeleg er dette ved 5-10-utdanninga, der det ikkje er obligatorisk. Med den siste reforma har fagmiljøa ved institusjonane fått større kontroll over fagutviklinga ved overføringa av ansvaret for dei nasjonale retningslinjene til UHR. Norskfaget har òg, sannsynlegvis på godt og vondt, mista noko av den politiske interessa til matematikkfaget, som er gjort viktigare ved inntak til utdanningane, og som har fått sentralgitte eksamenar. Det siste er ei form for styring som fort kan setje nasjonale retningslinjer på sidelinja. 
Analysane syner ganske stor utvikling i læringsutbyta frå 2010-2016. Ein del utviklingsdrag verkar fagleg sett logiske, medan andre kan vere meir paradoksale, som at ein svekker teoretiske tilnærmingar når ein i tekstproduksjonen går meir i forskingsbasert retning. Særleg viktig er det at ein har styrkt dei historiske tilnærmingane samstundes som kunnskap om nasjonale prøver får eigne kompetansemål i lærarutdanningsfaget. Skal norskfaget på sikt halde posisjonen sin som det største skulefaget, vil det kunne bli avgjerande at ein greier å balansere ferdigheitsfokuset med kritisk tenking og danningsperspektiv i utdanninga av komande norsklærarar.

\section{Om forfattaren}

Magne Rogne er førsteamanuensis i norskdidaktikk ved Universitetet i Stavanger. Han har doktorgrad i lesevitskap frå 2012 med ei avhandling om norskfagets tekstomgrep, og han var prosjektleiar for Følgjegruppa for lærarutdanningsreforma 2010-2015. Forskingsinteressene har vore knytt både til utvikling av lærarutdanning generelt og norskfaget i ulike skuleslag - dei siste åra særleg retta mot digitale tekstar. Siste publikasjon er den vitskaplege antologien Multimodalitet i skole- og fritidstekstar, som han redigerte i lag med Lars Rune Waage (Fagbokforlaget, 2018).

Institusjonstilknytning: Institutt for grunnskulelærarutdanning, idrett og spesialpedagogikk, Fakultetet for utdanningsvitskap og humaniora, Universitetet i Stavanger, Postboks 8600, 4036 Stavanger

E-post: magne.rogne@uis.no

\section{Referansar}

Bakke, J.H. \& Kverndokken, K. (2014). Muntlig bruk av språket. I Jansson, B.K. og Traavik, H. (red.) Norskboka 2. Norsk for grunnskolelererutdanning 1-7. Universitetsforlaget.

Bjellås, P. (2014). Talemål, didaktikk og danning. I Nordstoga, S. og Kruse, K.L. (red.) Den moglege sjølvoverskridinga. Norskfaget som danningsfag. Abstrakt forlag.

Budal, I. B. (red.). (2015). Språk i skolen. Grammatikk, retorikk, didaktikk. LNU Fagbokforlaget.

Dahl, Helge. (1959). Norsk lererutdanning fra 1814 til i dag. Universitetsforlaget.

Delsing, L-O. \& Åkesson, K.L. (2005) Håller språket ihop Norden? En forskningsrapport om ungdomars förståelse av danska, svenska och norska. TemaNord. http://norden.divaportal.org/smash/get/diva2:700762/FULLTEXT01.pdf

Eide, O. (2017). Norsk munnleg - grunnleggande for demokratisk deltaking og danning. I Fondevik, B. og Hamre, P. (red.) Norsk som reiskaps- og danningsfag. Samlaget.

Eritsland, A.F. (2007). Skrivepedagogikk. Teori og metode. Samlaget.

Fodstad, L.A. og Mortensvik, A. (2018). Øvelser i empati og kulturell tilgang.

Avgangselevers legitimering av arbeid med eldre skjønnlitteratur i videregående 
opplæring. I Acta Didactica 3/2018.

https://www.journals.uio.no/index.php/adno/article/view/6149

Følgjegruppa (2011). Frå allmennlæerer til grunnskulelærar. Innfasing og oppstart av nye grunnskolelcerarutdanningar. http://ffl.uis.no/.

Følgjegruppa. (2013). Drivkraft i utviklinga av lærarprofesjonen? Framsteg og utfordringar for grunnskulelcrarutdanningane. http://ffl.uis.no/.

Følgjegruppa. (2015). Grunnskulelcrarutdanningane etter fem år. Status, utfordringar og vegar vidare. http://ffl.uis.no

Hamre, P. (2014). Norskfaget og skjønnlitteraturen. Ein studie av norskfaglege normtekstar 1789-2013. Doktorgradsavhandling UiB.

Hamre, P. (2017). Norskfaget som reiskaps- og danningsfag. I Fondevik, B. og Hamre, P. (red.) Norsk som reiskaps- og danningsfag. Samlaget.

Haugen, T.A. (2019). Funksjonell grammatikk som metaspråk i skulen - ei moglegheit for djupnelæring i arbeid med språk og tekst. I Acta Didactica 3/2019. https://www.journals.uio.no/index.php/adno/article/view/6240

Hårstad, S. (2016). «[...] en enkel og saklig innføring i norsk språkhistorie». Språkhistorie som norskdidaktisk emne - et faghistorisk utsyn. I Acta Didactica 3/2016. https://www.journals.uio.no/index.php/adno/article/view/2852

Iversen, H.M, Otnes, H, Solem, M.S. (2004). Grammatikken i bruk - i tekst og i klasserom. Cappelen Akademisk Forlag.

Jahr, E.H. (1984). Talemålet i skolen: en studie av drøftinger og bestemmelser om muntlig språkbruk i folkeskolen (fra 1874 til 1925). Novus.

Karseth, B. \& Sivesind, K. (2009). Læreplanstudier - perspektiver og posisjoner. I Dale, E.L. (red.) Lcereplan i et forskningsperspektiv (s. 23-61). Universitetsforlaget.

KD (Kunnskapsdepartementet). (2010a). Forskrift om rammeplan for grunnskolelcrareutdanningene for 1-7 trinn og 5-10 trinn.

http://www.regjeringen.no/upload/KD/Rundskriv/2010/Forskrift_rammeplan_grunnskolel aererutdanningene.pdf.

KD (Kunnskapsdepartementet). (2010b). Nasjonale retningslinjer for grunnskolelærerutdanningen 1. - 7. trinn. https://www.regjeringen.no/globalassets/upload/kd/rundskriv/2010/retningslinjer_grunnsk olelaererutdanningen_1_7 trinn.pdf?id=2120258.

KD (Kunnskapsdepartementet). (2010c). Nasjonale retningslinjer for grunnskolelcererutdanningen 5. - 10. trinn. https://www.regjeringen.no/globalassets/upload/kd/rundskriv/2010/retningslinjer_grunnsk olelererutdanningen_5_10_trinn.pdf?id=2120265.

KD (Kunnskapsdepartementet). (2014). https://www.regjeringen.no/no/aktuelt/Skjerperopptakskravene-til-larerutdanningene/id2001847/.

KD (Kunnskapsdepartementet). (2016a). Forskrift om rammeplan for grunnskolelcererutdanning for trinn 1-7. https://lovdata.no/dokument/SF/forskrift/201606-07-860.

KD (Kunnskapsdepartementet). (2016b). Forskrift om rammeplan for grunnskolelererutdanning for trinn 5-10. https://lovdata.no/dokument/SF/forskrift/201606-07-861.

Kress, G. (2003). Literacy in the New Media Age. Routledge.

KUD (Kyrkje- og undervisningsdepartementet). (1965). Undervisningsplan for den 2-årige og 4- årige lærarskolen. Grøndahl \& Søns Forlag.

KUD (Kyrkje- og undervisningsdepartementet). (1980). Studieplan for allmennlærarutdanning. Universitetsforlaget. 
KUF (Kirke-, utdannings- og forskningsdepartementet). (1994). Rammeplan for 4-årig allmennlæererutdanning 1992. Justert utgave.

KUF (Kirke- undervisnings- og forskningsdepartementet). (1999). Rammeplan for allmennlcererutdanning. Norgesnettrådet.

Kulbrandstad, L.A. (1998). Språkets mønstre. Grammatiske begreper og metoder. Universitetsforlaget.

Lærarskulen (1939). Lærarskulen. Lov, reglement og undervisningsplaner. Grøndahl \& Søns Forlag.

Lærarutdanningsrådet. (1986). Studieplan for allmennlæerarutdanning .

Madssen, K-A. (1999). Morsmålsfagets normtekster. Et skolefag blir til- norskfaget mellom tradisjon og politikk. Doktorgradsavhandling. NTNU.

Matre, S., Sjøhelle, D.K. og Solheim, R. (red.) (2012). Teorier om tekst i møte med skolens lese- og skrivepraksiser. Universitetsforlaget.

Munthe, E. \& Rogne, M. (2016). Norwegian teacher education: Development, steering and current trends. I B. Moon (red.) Do Universities have a Role in the Education and Training of Teachers? An international analysis of policy and practice (s. 35-55). Cambridge University Press.

Maagerø, E. (2005). Språket som mening. Innføring i funksjonell lingvistikk for studenter og lcrere. Universitetsforlaget.

Nergård, M.E. \& Tonne, I. (2008). Språkdidaktikk for norsklærere. Universitetsforlaget.

Nordstoga, S. (1998). Litteraturhistorie og L7. Ei fagdidaktisk innføring. Tano Aschehoug.

Nordstoga, S. (2003). Inn i norskfaget. Om faget, debatten og didaktikken. Abstrakt.

Norsk Lovtidende. (1891). (2. avd). Undervisningsplan for Seminarierne.

NOU. (1974). Nr. 58 - Lcrarutdanning. Universitetsforlaget.

Ongstad, S. (2004). Språk, kommunikasjon og didaktikk. Norsk som flerfaglig og fagdidaktisk ressurs. Fagbokforlaget.

Ongstad, S. (2012). Trender i internasjonal morsmålsdidaktisk forskning. I Norsk pedagogisk tidsskrift nr. 3/2012.

Osdal, H. \& Madssen, K-A. (2014). Norskfaget i GLU 5-10: Ei undersøking basert på tilsende styringsdokument frå fem lærarutdanningsinstitusjonar. I Lœrerutdanningsfagene norsk, engelsk, naturfag og kroppsøving. Delrapport 1: Følgegruppen. http://ffl.uis.no/.

Rogne, M. (2005). Norskfaget i allmennlærarutdanninga. I Lea, M. (red). Vekst og utvikling. Lerarutdanninga i Stavanger 50 år. UiS - Tidvise skrifter.

Rogne, M. (2008). Mot eit moderne norskfag. Tekstomgrepet i norskplanane. I Acta Didactica 1/2008. https://www.journals.uio.no/index.php/adno/article/view/1021

Rogne, M. (2012). Mot eit moderne norskfag - ein studie i norskfagets tekstomgrep. Doktorgradsavhandling ved Universitetet i Stavanger, nr. 152.

Rogne, M. (2017). Digitale tekstar i norskfaget. Ein analyse av læreplanar og eksamensoppgåver. I Fondevik, B. og Hamre, P. (red.) Norsk som reiskaps- og danningsfag. Samlaget.

Rogne, M. \& Munthe, E. (2017). Ei forskingsbasert grunnskulelærarutdanning. I FoU i praksis. ISSN 1504-6893. Hefte 1. s. 63-83. https://fou.portfolio.no/

Rønning, M., Sørland, K, Vaagen. O. (2014). Norsk grammatikk for grunnskolelcereren. Cappelen Damm akademisk.

Selander, S. (2010). En hermeneutisk läsning av pedagogiska texter. I: Knudsen, S.V. \& Aamotsbakken, B. (red.) Teoretiske tilnœrminger til pedagogiske tekster (s. 32-51). Høyskoleforlaget.

Skaug, S. \& Blikstad-Balas, M. (2019). Hele tekster versus utdrag - hvilke tekster velger norsklærerne? I Nordic Journal of Literacy Research. 1/2019. https://nordicliteracy.net/index.php/njlr/article/view/1566 
Skjelbred, D. (2010). Fra Fadervår til Facebook. Skolens lese- og skriveopplering i et historisk perspektiv. Fagbokforlaget.

Smidt, J. (2018). Norskfaget mellom fortid og framtid. Scene og offentlighet. LNU Fagbokforlaget.

Statsseminarier. (1891). Ncermere bestemmelser angaaende statsseminarier og lcererprøver. P.T. Mallings boghandel.

UDIR (Utdanningsdirektoratet). (2006). Læreplan i norsk (NOR1-01). http://www.udir.no/kl06/NOR1-01

UDIR (Utdanningsdirektoratet). (2013). Læreplan i norsk (NOR1-05). http://www.udir.no/kl06/NOR1-05

UDIR (Utdanningsdirektoratet). (2019). https://www.udir.no/eksamen-ogprover/prover/rammeverk-for-nasjonale-prover/hva-er-nasjonale-prover/

UDIR (Utdanningsdirektoratet). (2020) Læreplan i norsk (NOR1-06). https://www.udir.no/lk20/nor01-06

UFD (Utdannings- og forskningsdepartementet). (2003). Rammeplan for allmennlcrerutdanningen

UHR (Universitets- og høgskolerådet). (2016a). Nasjonale retningslinjer for grunnskolelcererutdanning 1. - 7. trinn. http://www.uhr.no/documents/Godkjent_1_7_010916.pdf

UHR (Universitets- og høgskolerådet). (2016b). Nasjonale retningslinjer for grunnskolelcererutdanning 5. - 10. trinn. http://www.uhr.no/documents/Godkjent_5_10 010916.pdf

UHR. (2019). E-post frå UHR ved Dagny Kristine Johnson Hov til Magne Rogne, datert 1.8.2019.

Utdanningsdirektoratet. (2006). Framtidas norskfag. Språk og kultur i eit fleirkulturelt samfunn. Rapport frå ei gruppe nedsett av Utdannings- og forskingsdepartementet. https://www.regjeringen.no/globalassets/upload/kilde/kd/rap/2006/0001/ddd/pdfv/269917 -norskrapporten.pdf

Vinje, E. (2005). Om kanon i litteraturundervisninga. I Nicolaysen, B.K. og Aase, L. (red.) Kulturmøte i tekstar: litteraturdidaktiske perspektiv. Samlaget.

Aamotsbakken, B. \& Knudsen, S.V. (2011). Å tenke teori. Om leseteorier og lesing. Gyldendal Akademisk.

Aase, L. (2002). Norskfaget blir til. Den larde skolens morsmålsundervisning og danningstradisjoner fram til 1870. LNU Fagbokforlaget.

Aase, L. (2005). Norskfaget - skolens fremste danningsfag? I Børhaug, K., Fenner, A-B. og Aase, L. (red.) Fagenes begrunnelser. Skolens fag og arbeidsmåter i danningsperspektiv. Fagbokforlaget. 


\section{Vedlegg 1}

\section{Norsk 1-7 Samanlikning}

Norsk 1

\begin{tabular}{|c|c|c|c|c|}
\hline 2010 & & 2016 & & \\
\hline \multicolumn{3}{|c|}{ - $\quad$ Språk } & - $\quad$ Språk & \\
\hline & & barns språkutvikling $1^{*}$ & 0 & språket som system 1 \\
\hline & 0 & språk som system 5 & 0 & språket i bruk 1 \\
\hline & 0 & språket i bruk 5 & 0 & barns språkutvikling 2 \\
\hline & 0 & talemålsvariasjon 5 & 0 & språkleg identitet 3 \\
\hline & 0 & skriftspråknormering 5 & 0 & norsk som andrespråk 3 \\
\hline & 0 & fleirspråklegheit 6, 31 & 0 & fleirspråkleg praksis 3 \\
\hline & 0 & norsk som andrespråk 6 & 0 & språkvanskar 12 \\
\hline & 0 & retorisk kunnskap 19 & & \\
\hline
\end{tabular}

(KD, 2010b, s. 29ff)

(UHR, 2016a, s. 28f)

* Tala bak omgrepa syner til plassering i rekkjefølgja av læringsutbyteformuleringar (eigennummerert). 